\title{
Pharmaceutical Quality/CMC Compendial Method Verification Indicator Terminology
}

National Cancer Institute

\section{Source}

National Cancer Institute. Pharmaceutical Quality/CMC Compendial Method Verification

Indicator Terminology. NCI Thesaurus. Code C133850.

A category of terminology used to qualify the information pertaining to compendial method verification indicators in the framework of the Pharmaceutical Quality/Chemistry, Manufacturing and Controls documents. 